|| ISSN(online): 2589-8698 || ISSN(print): 2589-868X ||

International Journal of Medical and Biomedical Studies

Available Online at www.ijmbs.info

NLM (National Library of Medicine ID: 101738825)

Index Copernicus Value 2019: 79.34

Original Research Article

Volume 5, Issue 9; September: 2021; Page No. 01-04

\title{
THE MANAGEMENT OF SNAKE BITE AND THEIR OUTCOME WITH DIFFERENT VARIABLES
}

\author{
Dr. Ramesh Kumar Jakhar ${ }^{1}$, Dr. Arvind Jain ${ }^{2}$ \\ ${ }^{1}$ MBBS MD, Junior Specialist, Medicine, Department of Medicine, Dr. S.N. Medical College, Jodhpur \\ ${ }^{2}$ Senior Professor and Unit Head, Medicine, Department of Medicine, Dr. S.N. Medical College, Jodhpur
}

Article Info: Received 28 June 2021; Accepted 29 August 2021

DOI: https://doi.org/10.32553/ijmbs.v5i9.2163

Corresponding author: Dr. Ramesh Kumar Jakhar

Conflict of interest: No conflict of interest.

\begin{abstract}
Background: Snake Bite is a life-threatening medical emergency \& major public health issue throughout the world and especially in tropical countries like India. Snake bite which is a substantial cause of death in rural areas of developing countries, is a neglected public health problem.

Methods: The study include the patient of snake bite who is admitted in department of medicine of M.D.M. Hospital attached to Dr S. N. Medical College Jodhpur during the period of one year January 012018 to December 31, 2018. Patients were enrolled after obtaining an informed consent and meeting inclusion criteria.

Results: Maximum number of the cases did not receive any first aid and ASV\& Pain killer was the most common component of the first aid. Two third of the cases were bitten by Viper snakes while one third by Cobra and Krait collectively. ASV dose was given as per the case response and in ASV dose of 30-50 VIAL was injected in majority of the victims (38.56). 30-50 VIAL was injected in majority of the victims. At time of hospital admission WBCT is normal in 52 patients (33.09\%) while 101 patients had WBCT more than 20 min.

Conclusion: Snakebite, an important occupational hazard, though preventable in principle remains to be one of the common medical emergencies. Primary prevention by imparting information regarding quick transport, correct first aid measures and training of primary level health workers can drastically bring down the mortality of this neglected tropical disease.

Keywords: Snake bite, ASV, Viper.
\end{abstract}

\section{Introduction}

Snake Bite is a life-threatening medical emergency \& major public health issue throughout the world and especially in tropical countries like India. Snake bite which is a substantial cause of death in rural areas of developing countries, is a neglected public health problem. ${ }^{1}$

In 2009, snake-bite was included in the WHO's list of neglected tropical diseases of SE Asia, confirming the experience in many parts of this region that snake-bite is a common occupational hazard of farmers, plantation workers and others, resulting in tens of thousands of deaths each year and many cases of chronic physical handicap.(WHO, 2007; Williams, 2010). Much is now known about the species of venomous snakes responsible for these bites, the nature of their venoms and the clinical effects of envenoming in human patients. ${ }^{2}$

Largest number of deaths reported in India was occurred in Bengal, Tamil Nadu, Bihar, Maharashtra and Rajasthan. Therefore, there is an imperative need to prevent death due to snakebite in India. Antisnake Venom (ASV) and its rational use is the only definitive treatment to neutralize venom in circulation and in tissue fluid to save life in snake bite cases. ${ }^{3}$ There are many causes attributed to high snake bite mortality. Lack of adequate training and knowledge of doctors in rational use of ASV is very important ${ }^{7}$ Snakes are different in different geographical area hence having different clinical manifestation for which different ASV is used. Most of the important text books and Journals from western countries deal with snakes and snake bite of their country and not of India. ${ }^{4}$ In 1999 WHO has recommended a guideline for managing snake bite cases. In 2005 WHO has recommended a guideline for treating snake bite cases in South- East Asia which is not available in commonly used text books of medicine and even it is not mentioned in product information notes attached to ASV vials. ${ }^{5}$

It is important to decide not only the proper regimens but also the modality of treatment in complication of snake bite cases. It is important to know variable clinical features and their complication as they occur in each case Hence, the objective of this study is to observe the management of snake bite and their outcome with different variables. 


\section{Material and Methods}

The study include the patient of snake bite who is admitted in department of medicine of M.D.M. Hospital attached to Dr S. N. Medical College Jodhpur during the period of one year January 012018 to December 31, 2018. Patients were enrolled after obtaining an informed consent and meeting inclusion criteria. Demographic characteristics of the patients and the snake bite event such as age, gender, time of bite, site of bite, bite-to-hospital time were recorded. Symptoms and signs such as local swelling, nausea, vomiting, ptosis, tachycardia, hypotension, impending respiratory failure by single breath count (SBC), bite to injection time of anti-snake venom (ASV), ASV treatment before referral, total dose of anti-snake venom administered, and duration of stay were documented. Most important investigation to be performed in vasculotoxic snake bite is 20-minute whole blood clotting time (20 minute WBCT) which helps in early detection of coagulopathy and subsequent acute renal failure.

The 20-min whole blood clotting test (20 WBCT): The 20 WBCT is a simple bedside test of coagulopathy to diagnose viper envenomation and rule out elapid bite. It requires a new clean, dry test tube made up of simple glass that has not been washed with any detergent. A few milliliters of fresh venous blood are drawn and left undisturbed in the test tube for $20 \mathrm{~min}$; the tube is then tilted gently. If the blood is still liquid after $20 \mathrm{~min}$, it is evidence of coagulopathy and confirms that the patient has been bitten by a viper. Cobras or kraits do not cause ant hemostatic symptoms. ${ }^{29}$ Complete blood count, liver function test, renal function tests, urine examination to rule out hematuria, coagulation profile (PT and INR) were also done. Primary outcome was defined in the form of survival or non-survival. Prognostic factors were compared in survived and no survived groups.

\section{Inclusion criteria}

All patients who presented with a history of snake bite or showing evidence of envenomation either systemic or local. Hematological envenomation is said to be present when patient had a clotting time of $>20$ min with history of snake bite. in casualty department and outdoor at MDM HOSPITAL (Dr. S N Medical college) were included in the study.

\section{Exclusion criteria}

1. Patient not willing to participate in study.

2. Preexisting hematological or coagulation problem

3. Snake bite case with WBCT $<20 \mathrm{~min}$

4. Unknown bite with WBCT $>20$ min

\section{Results}

In our study it has been observed that the age of study participants $(n=153)$ ranged between 14 to 85 years. Participants are divided into five groups according to increasing age. Maximum number of participants $53(34.64 \%)$ lies under (15-30) years age group and minimum number of participants lies under age group lies under age group of $>60$ years which are 08(5.23\%). Male cases were $82(53.59 \%)$ and mean age were of 36.84 years. Female cases were of $71(46.41 \%)$.and mean age were of 37.56 years.

Table 1: First AID/ Treatment Provided Prior to Presentation

\begin{tabular}{|l|l|l|}
\hline First Aid & Frequency & Percentage \\
\hline ASV & 08 & 5.23 \\
\hline ASV \&Pain killer & 64 & 41.83 \\
\hline Pain killer & 13 & 8.50 \\
\hline Tourniquet & 10 & 6.54 \\
\hline Local Medication & 04 & 2.61 \\
\hline None & 54 & 35.29 \\
\hline Total & 150 & 100 \\
\hline
\end{tabular}

It is observed that ASV and first aid was provided to (08) cases and ASV and pain killer treatment was provided to (64) cases, only pain killer as first aid was given to the cases (13) and tourniquet were provided to the cases (10) cases, local medication was given to only (04) cases. And no treatment was provided prior to presentation of cases (54).

Table 2: Distribution of cases on the basis of snake types

\begin{tabular}{|l|l|l|}
\hline Type & Frequency & Percentage \\
\hline Viper & 112 & 73.20 \\
\hline King Cobra & 29 & 18.95 \\
\hline Krait & 12 & 7.84 \\
\hline Total & 153 & 100.0 \\
\hline
\end{tabular}

In our study it is observed that most of the snake bite cases (73.20\%) viper snake. And in 29 cases of snake bite were by king cobra and 12 cases of snake bite were by krait snake. 
Table 3: ASV DOSE (Vial) Given As Per Response (Normalization of WBCT/ Reversal of sign of Envenomization)

\begin{tabular}{|l|l|l|}
\hline ASV DOSE(VIAL) & Frequency & Percentage \\
\hline $10-20$ vial & 10 & 6.54 \\
\hline $20-30$ vial & 36 & 23.53 \\
\hline $30-50$ vial & 59 & 38.56 \\
\hline $50-80$ vial & 44 & 28.76 \\
\hline$>80$ vial & 04 & 2.61 \\
\hline Total & 150 & 100 \\
\hline
\end{tabular}

According to the response from the victims ASV dose(vial) given. In this study observed that (10-20) vial ASV dose were given to the cases (10), (20-30) vial dose given to the cases (36), (30-50) vial ASV dose were given to the cases (59). (50-80) vial ASV dose given to the cases of (44), and (>80) vial ASV dose were given to 04 victims.

Table 4: Sensitivity to ASV

\begin{tabular}{|l|l|l|}
\hline Sensitive to ASV & Frequency & Percentage \\
\hline Yes & 07 & 4.58 \\
\hline No & 146 & 95.42 \\
\hline Total & 153 & $100.0 \%$ \\
\hline
\end{tabular}

It was found that most of the cases $146(95.42 \%)$ were not sensitive to ASV and only cases (07) were sensitive to the ASV.

Table 5: WBCT at the time of Hospital admission

\begin{tabular}{|l|l|l|}
\hline WBCT at the time of Hospital admission & Frequency & Percentage \\
\hline$<20 \mathrm{~min}$ & 41 & 26.80 \\
\hline$>20 \mathrm{~min}$ & 112 & 73.20 \\
\hline Total & 153 & 100 \\
\hline
\end{tabular}

In most of the cases (101) WBCT at hospital admission were greater than 20 minutes and in cases (52) WBCT at time of hospital admission were less than 20 minutes.

Table 6: WBCT after Administration of $1^{\text {st }}$ Dose of ASV (10 Vials)

\begin{tabular}{|l|l|l|}
\hline WBCT AT 24 HR & Frequency & Percentages \\
\hline$<20 \mathrm{~min}$ & 46 & 30.07 \\
\hline$>20 \mathrm{~min}$ & 107 & 69.93 \\
\hline Total & 153 & 100.0 \\
\hline
\end{tabular}

It is observed that WBCT after administration of 1st dose of ASV in cases (46) were less than 20 minutes and greater than 20 minutes in cases (107).

Table 7: Normalization of WBCT after administration of ASV

\begin{tabular}{|l|l|l|}
\hline Normalization of WBCT after & Frequency & Percentages \\
\hline $01-24 \mathrm{Hrs}$ & 05 & 3.27 \\
\hline $25-48 \mathrm{Hrs}$ & 29 & 18.95 \\
\hline $49-72 \mathrm{Hrs}$ & 44 & 28.76 \\
\hline $73-96 \mathrm{Hrs}$ & 18 & 11.76 \\
\hline$\geq 96 \mathrm{Hrs}$ & 16 & 10.46 \\
\hline
\end{tabular}

\section{Discussion}

The present study comprises of 153 cases who presented with history of snake bite with sign of envenomation during the study period. A meticulous history. Clinical examination and laboratory investigations were carried out on the day of admission and regularly thereafter. Cases were followed till the final outcome in the form of discharge or death. Data records include the patients' characteristics such as symptoms and signs complications, dose of ASV, duration of stay and final outcome. This data was analyzed for predicting survival.

ASV pain killer (41.83) formed the main component of the first aid. Worryingly $35.29 \%$ victims were not provided with any first aid sort of thing. Remaining of the victims were provided with Pain killer (8.5\%), Torniqute(6.54\%), ASV (5.23\%) and local medication (2.61\%). Same form of first aid treatment was observed by Lahori et al ${ }^{6}$, Saini et $\mathrm{al}^{7}$ and Kulkarni and Anees et $\mathrm{al}^{8}$. 
$73.20 \%$ of the incidents involved Viper snake as compared to King Cobra snake (18.95\%) and Krait $(7.84 \%)$. Shyna K.P. et $\mathrm{al}^{9}$ have also found in their study that Viper snake accounted for highest number of bites followed by Krait and Cobra snakes.

ASV dose of 30-50 vial was injected in majority of the victims (38.56). 30\% cases required less than 30 vial for response from the symptom of snake bite while in contrary to the Indian national guideline(2016) $70 \%$ cases required ASV more than 30 vial this shows that there may regional variation of the requirement of ASV. $95.42 \%$ were not sensitive to ASV dose and only $4.58 \%$ reacted to it (Table 14).Range of hypersensitivity to ASV was as low as $1.3 \%$ to as high as $52.0 \%$ as observed by Kulkarni and Anees et $\mathrm{al}^{8}$ and Theakston et $\mathrm{al}^{10}$ respectively. No allergic reaction to repeated ASV injections was reported by Nigam et $\mathrm{al}^{11}$. The probable reason for this may be administration of corticosteroids to 14 patients of Cobra and Viper bite out of 22 poisonous snake bite cases by the author. Tariang et $\mathrm{al}^{12}$ have reported that the mean dose ASV required to manage a case with envenomation effectively is 4.7 vials. They have also reported in their series that the neurotoxic envenomation requires higher dose of ASV. Menon JC et $\mathrm{al}^{13}$ have also used ASV more than 50 vials or 500 $\mathrm{ml}($ maximum) for hematological and 30 vials for neurotoxic poisoning(maximum).

At time of hospital admission WBCT is normal in 41 patients $(26.79 \%)$ all of them were Cobra \& Krait cases(Table 15). 112(73.21\%)patients had WBCT more than 20 min. Furthermore, in most of the cases (28.76\%) WBCT got normal within $49-72$ hours while $3.27 \%$ cases took $01-24$ hours, $18.95 \%$ cases took $25-48$ hours, $11.76 \%$ cases took $73-96$ cases and $10.46 \%$ took greater than 96 hours.

\section{Conclusion}

Snakebite, an important occupational hazard, though preventable in principle remains to be one of the common medical emergencies. Primary prevention by imparting information regarding quick transport, correct first aid measures and training of primary level health workers can drastically bring down the mortality of this neglected tropical disease.

\section{References}

1. Whitaker Z. 1990. Snakeman . Penguin Books Ltd. 192 pp. ISBN 0-14-014308-

2. Dr Asha Shah H \& FW Dept, Govt .Of Gujrat Snake Bite Management Protocol Guideline 2016

3. Vijeth SR, Dutta TK, Shahapurkar J. Correlation of renal status with haematological profile in viperine bite. Am J Trop Med Hyg 1997;56:168-70.

4. Barry S, Gold Md et al. Bites of venomous snakes. Engl J Med 2002; 347 (5) : 347-56.

5. Warrell DA. Injuries, envenoming, poisoning, and allergic reactions caused by animal. Oxford textbook of medicine 1984.1984;635-640.

6. Lahori UC, Sharma DB, Gupta KB, et al Snake bite poisoning in children. Indian Paediatrics 1981;18(3): 193-197.

7. Saini RK, Sharma $S$, Singh $S$, et al Snake bite poisoning: A preliminary report. Journal of the Association of Physicians of India 1984;32(2): 195197.

8. Kulakarni ML, Anees S. Snake venom Poisoning, experience with 633 patients. Indian Paediatr. 1994;31:1239-43

9. Shyna K. P., Sudhakaran K., Mohammed M. T. P.et al A clinical profile of poisonous snake bite in children of North Kerala, India -3291.ijcp 20180025

10. Theakston RD, Warrell DA, Griffiths E. Report of a WHO workshop on the standardization and control of antivenoms. Toxicon. 2003;41:541-57

11. Nigam P, Tandon VK, Rajendra Kumar, et al. Snake bite - A clinical study. The Indian Journal of Medical Sciences 1974; 27: 697-704

12. Tariang DD, Philip PT, Alexander, et al. Randomized controlled trial on the effective dose of anti- snake venom in cases of snake bite with systemic Envenomation. JAPI 1999;47:369-371.

13. Menon JC, Joseph JK, Jose MP, et al. Clinical Profile and Laboratory Parameters in 1051 Victims of Snakebite from a Single Centre in Kerala, South India. JAP I 2016; 63:22-29. 